\title{
Compatibility of Different Composite Shades with VITA Shade Guide
}

\author{
Ali A Razooki Al-Shekhli* and Israa A AlAyoobi \\ Ajman University, UAE
}

Submission: October 15, 2018; Published: November 15, 2018

*Corresponding author: Ali A Razooki Al-Shekhli, Deputy Dean \& Associate Prof College of Dentistry, Ajman University, UAE

Abstract

Objective: The demand for esthetic restorations has increased over the past years, and one the most common esthetic restorations used are composite resin, therefore new dental composites are continuously being introduced by manufacturers in order to improve the esthetic quality of dental fillings. The aim of this study was to measure the compatibility of different composite shades of some dental composites with electronic VITA shade guide.

Materials and Method: Two shades of three different brands of dental composites were selected in this study A1 \& A3.5: Composan LCM A1, Composan LCM A3.5, IvoclarVivadent A1, IvoclarVivadent A3.5, OliREVO A1, OliREVO A3.5. 10 samples were prepared from each composite shade (total of 60 samples) and cured for 40 seconds. The samples made into round disk shape with dimensions of $5 \times 2 \mathrm{~mm}$. Shade measurement was done using a spectrophotometer "VITA EASYSHADE V"electronic VITA shade guide. Data were analyzed using percentage of error method.

Results: Composan LCM shades were the least compatible with VITA shade guide, on the other hand OliREVO composite showed intermediate compatibility, while TetricEvoCreamIvoClar-Vivadent had showed the highest compatibility with VITA shade guide.

Conclusion: Composition and translucency of dental composite may affect their shades and compatibility with VITA Shade guide. Also, some manufacturers may have used different shade guide systems other than VITA shade guide (s) to measure the shades of their products.

Keywords: Shade; Compatibility; VITA; Composite

\section{Introduction}

Composite is defined as a combination of two or more materials that results in a material with better properties and characteristics [1]. The demand for esthetic restorations has increased over the past years and one the most common esthetic restorations used are composite resin [2]. New dental composites are continuously being introduced by manufacturers in order to improve the esthetic quality of dental filling.

One of the major challenges of esthetic dentistry is to achieve a perfect color match between the natural tooth and the restoration [3]. First previous studies demonstrated that visual shade matching is subjective [4], and the results vary among the observers and within the individual observer. Secondly, the light source influences shade matching because of the spectralcomposition of the light reflecting off an object affects the perceived color as a result of the Metamerism [5]. Third, shade guides are not uniformly distributed in the CIELAB color space and do not cover the entire range of natural tooth shades [6].Finally, enamel translucency and the polychromatic nature of dentin interact to produce depth of shade that is difficult to characterize [7].Therefore there have been great improvements in shades guides, shade taking devices, and researches in the area of human color vision have improved the potential of achieving excellent color matched restoration in order to overcome this challenge [8]. The aim of this study was to measure the compatibility of different composite shades of some dental composites with electronic VITA shade guide.

Materials and Method

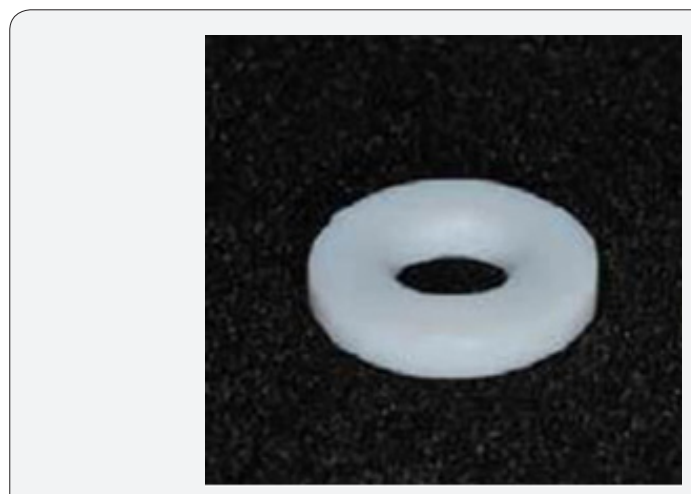

Figure 1: Teflon Mold (5x2mm).

Three different composite brands were selected for this study, two shades from each (total of 6 tubes): Composan LCM A1, Composan LCM A3.5, IvoclarVivadent A1, IvoclarVivadent A3.5, 
OliREVO A1 and OliREVO A3.5. 10 composite specimens were prepared from each composite shade $(n=10)$ using a standard Teflon mold with dimensions of $5 \mathrm{~mm}$ in diameter and $2 \mathrm{~mm}$ in thickness (total of 60 samples were prepared) Figure 1.

Composite was placed inside the Teflon mold and then pressed firmly against two glass slides, then each sample was light cured for 40 seconds using Ivoclar Bluephase light curing unit (20 seconds on each side) Figure 2.

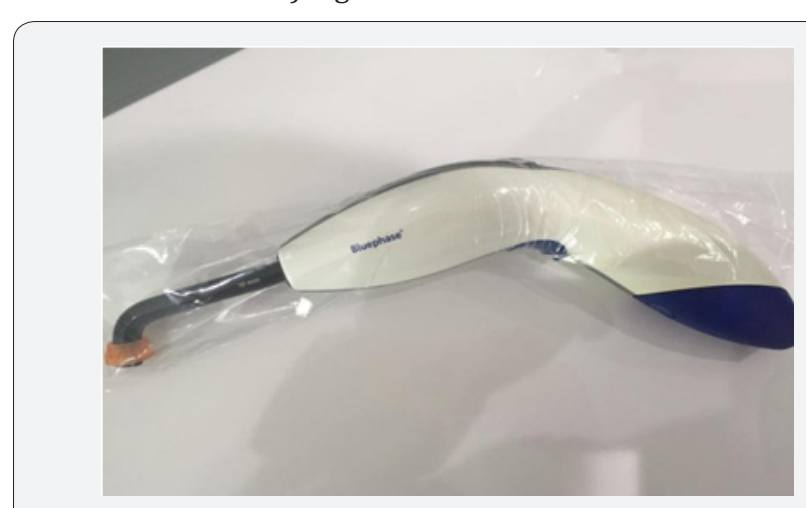

Figure 2: Ivoclar BluePhase light curing device.
The shade of each specimen was then measured using EasyShade VITA electronic shade guide and the results were recorded Figure 3. Then the Data (shades) obtained by the shade guide were converted to a numerical value by assuming a number equivalent to the corresponding shade according to the Table 1.

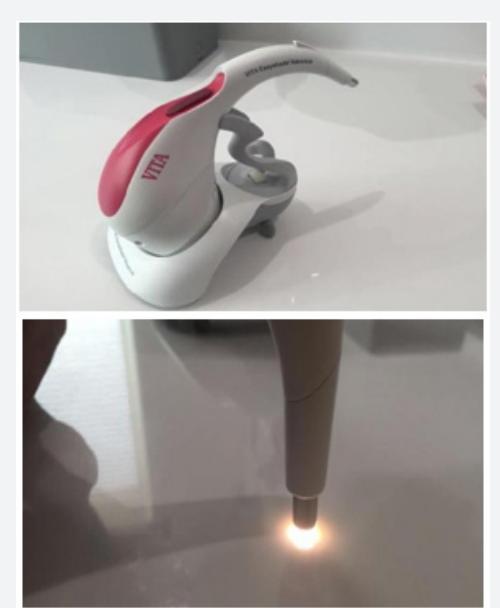

Figure 3: measuring the samples' shade using VITA Easy Shade electronic shade guide.

Table 1

\begin{tabular}{|c|c|c|c|c|c|c|c|c|c|c|c|c|c|c|c|c|}
\hline Shade & A1 & A2 & A3 & A3.5 & A4 & B1 & B2 & B3 & B4 & $\mathrm{C} 1$ & C2 & C3 & $\mathrm{C} 4$ & D2 & D3 & D4 \\
\hline Equivalent & 0 & 1 & 2 & 3 & 4 & 5 & 6 & 7 & 8 & 9 & 10 & 11 & 12 & 13 & 14 & 15 \\
\hline
\end{tabular}

Results

Table 2: Shade measurements results.

\begin{tabular}{|c|c|c|c|c|c|c|c|c|c|c|}
\hline Composite & S1 & S2 & S3 & S4 & S5 & S6 & S7 & S8 & S9 & S10 \\
\hline Composan A1 & B3 & B3 & B3 & B3 & B3 & B4 & B3 & B3 & B3 & B3 \\
\hline Composan A3.5 & A4 & A4 & A4 & A & A & A & A4 & A4 & C4 & C4 \\
\hline IvocClar A1 & A1 & A1 & A1 & A1 & A1 & A1 & A1 & A1 & A1 & A1 \\
\hline IvocClar A3.5 & A3.5 & A3.5 & A3.5 & A3.5 & A3.5 & A3.5 & A3.5 & A3.5 & A3.5 & A3.5 \\
\hline OliRevo A1 & A2 & A2 & A2 & A2 & A2 & A2 & A2 & A2 & A2 & A2 \\
\hline OliRevo A3.5 & A3.5 & A3.5 & A3.5 & A3.5 & A3.5 & A3.5 & A3.5 & A3.5 & A3.5 & A3.5 \\
\hline
\end{tabular}

Table 3: Numerical coding of composite shade and the calculated \% of error.

\begin{tabular}{|c|c|c|c|c|c|c|c|c|c|c|c|c|}
\hline Composite & S1 & S2 & S3 & S4 & S5 & S6 & S7 & S8 & S9 & S10 & Sum & \%error \\
\hline Composan A1 (0) & 7 & 7 & 7 & 7 & 7 & 7 & 7 & 7 & 7 & 7 & 71 & 7.1 \\
\hline Composan A3.5 (3) & 4 & 4 & 4 & 4 & 4 & 4 & 4 & 4 & 12 & 12 & 56 & 2.6 \\
\hline IvocClar A1 (0) & 0 & 0 & 0 & 0 & 0 & 0 & 0 & 0 & 0 & 0 & 0 & 0 \\
\hline IvocClar A3.5 (3) & 3 & 3 & 3 & 3 & 3 & 3 & 3 & 3 & 3 & 3 & 30 & 0 \\
\hline OliRevo A1 (0) & 1 & 1 & 1 & 1 & 1 & 1 & 1 & 1 & 1 & 1 & 10 & 1 \\
\hline OliRevo A3.5 (3) & 3 & 3 & 3 & 3 & 3 & 3 & 3 & 3 & 3 & 3 & 34 & 0.4 \\
\hline
\end{tabular}

Results were then converted into their respective numerical codes and the percentage of error was calculated as seen in Figure 4 (Table $2 \& 3$ ).

\section{Discussion}

In this study, we found that, two composite brands were not compatible with the VITA shade guide (Composan LCM and
OliREVO), as some differences were seen in matching with VITA standard, between different groups of the same shades and within the same groups andthis finding might be attributed to the difference in their composition as one previous study [9] confirms that different filler type resin composites showed different color characteristics, reflectance and $\mathrm{L}^{*} \mathrm{a}^{*} \mathrm{~b}^{*}$ distribution[10].Also, the fact that the composite bulk which is at the tips inside the 
composite tubes is usually dryer than the bulk which is found in the middle of the tube and this factor may have also affected the shade readings.

According to some previous studies $[9,11]$, characteristics of light transmittance and their influence on the color of various shades of resin composite had been evaluated indicating that, light transmittance characteristics play an important role in the final color of the resin composites, therefore the inherent translucency of resin composite may contribute to shade matching in our study. Other factors like thickness of the specimen may influence the depth to which light emitted by the shade measuring device can reach before reflecting to the device. The specific time of the day or the room lighting environment during which the shade selection was done may have a great impact on shade matching/ measuring [12]. In this study, some of the composite groups were incompatible with VITA shade guide, but other shades or brands may be compatible, so further studies concerning this field is needed. Finally, we can agree on the fact that there are no standardized international guidelines to which dental composite manufacturers to follow in fabricating their products particularly regarding the shade.

\section{Conclusion}

Within the limitations of our study, we found that not all composite brands being tested, were compatible with VITA shade guide standard.

\section{References}

1. FC Campbell (2010) Introduction to Composite Materials. Structural Composite Materials pp: 1-30.
2. Robert ALowe (2010) Composite Restorations: Subtleties in shade and technique pp. 2-8.

3. Sarah Shawky Mikhail (2011) Optical Properties of Two Brands of Composite Restorative Materials and Confirmation of Theoretical Predictions for Layering pp. 1-11.

4. Lindsey D, Wee AG (2007) Perceptibility and acceptability of CIELAB color differences in computer-simulated teeth. J Dent 35(7):593-599.

5. Corcodel N, Rammelsberg P, Moldovan O, Dreyhaupt J, Hassel AJ(2009) Effect of external light conditions during matching of tooth color: an intraindividual comparison. Int J Prosthodont 22 (1):75-77.

6. Bayindir F, Kuo S, Johnston WM, Wee AG(2007) Coverage error of three conceptually different shade guide systems to vital unrestored dentition. J.Prosthet Dent 98(3):175-185.

7. Ardu S, Feilzer AJ, Braut V, Benbachir N, Rizcalla N, et al. (2010) Pilot in vivo image spectro-photometric evaluation of optical properties of pure enamel and enamel-dentin complex. Dent Mater 26(7):205-210.

8. Brewer JD, Wee A, Seghi R (2004) DentClin North Am 48(2):341-358.

Advances in color matching.

9. Yumiko H, Takanobu S, Maki O, Susumu A, Masashi M, et al. (2009) Color characteristics of resin composite in different color modes and compositions. Journal of Oral Science 51(1):123-130.

10. Hunter Lab(2006) Versus CIE 1976 Lab 13(2):1-4.

11. Arikawa H, Fujii K, Kanie T, Inoue K (1988) Light transmittance characteristics of light-cured composite resins. Dent mater 14(6):405411.

12. Preston JD (1985) Current status of shade selection and color matching. Quintessence Int 16(1):47-58.

\section{Your next submission with Juniper Publishers will reach you the below assets}

- Quality Editorial service

- Swift Peer Review

- Reprints availability

- E-prints Service

- Manuscript Podcast for convenient understanding

- Global attainment for your research

- Manuscript accessibility in different formats

( Pdf, E-pub, Full Text, Audio)

- Unceasing customer service

Track the below URL for one-step submission https://juniperpublishers.com/online-submission.php 